УДК 659.1

DOI https://doi.org/10.32851/2708-0366/2021.7.14

Сокол П.М.

кандидат економічних наук, доцент кафердри маркетингу та міжнародного менеджменту, Дніпровський національний університет імені Олеся Гончара

Мосейко А.O. студентка,

Дніпровський національний університет імені Олеся Гончара

Sokol Polina, Moseyko Anastasia

Oles Gonchar Dnipro National University

\title{
ОСОБЛИВОСТІ ЗАСТОСУВАННЯ МЕРЕЖІ ІНТЕРНЕТ У РЕКЛАМНІЙ ДІЯЛЬНОСТІ ПІДПРИЄМСТВА
}

\section{FEATURES OF THE INTERNET APPLICATION IN ADVERTISING ACTIVITIES}

У статті розглянуто особливості застосування мережі Інтернет у рекламній діяльності реального підприємства. Проведено опитування та обтрунтовано необхідність застосування сучасного інструментарію Інтернету. Наголошено на необхідності більш ретельного вивчення сочіального медіамаркетингу як оптимального методу просування Інтернет-продукту для підприємств різного масштабу. Проведено аналіз діяльності у соціальних мережах та просування Інтернет-продукту через них на прикладі діючого суб' скта господарювання в умовах невизначеного конкурентного середовища. Доведено, щуо актуальність та необхідність використання изього методу сприяє підвищенню кон-

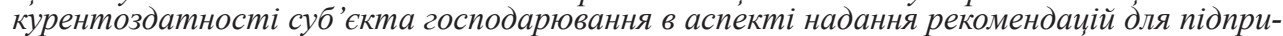
ємств різного масштабу в сучасному бізнес-середовищі, де соиіальний медіамаркетинг $\epsilon$ найбільш універсальним і дає змогу отримати актуальні та точні дані, розробити та обтрунтувати рекомендації, щзо відповідатимуть реальній ситуації на ринку. Обтрунтовано, щзо даний метод просування Інтернет-продукту є оптимальним у співвідношенні точності даних та витрат часу $і$ зусиль на його проведення.

Ключові слова: Інтернет-продукт, соціальний медіамаркетинг, аналіз діяльності підприсмства, соиіальні мережі, SWOT-аналіз.

В статье рассматриваются особенности использования Интернета в рекламной деятельности реального предприятия. Проведено исследование и обоснована необходимость использования современного инструментария Интернета. Подчеркнута необходимость более тмательного изучения маркетинга в социальных сетях в качестве оптимального метода продвижения Интернет-продукта для предприятий различных масштабов. Эта работа анализирует деятельность в соичальньх сетях по продвижению через них Интернет-продукта на примере существующего субъекта предпринимательской деятельности в неопределенной конкурентной среде. Доказано, что актуальность и необходимость использования этого метода способствует повышению конкурентоспособности субъекта предпринимательства с точки зрения предоставления рекомендаций для предприятий различных размеров в современной бизнесе-среде, где маркетинг сочиальньх сетей является наиболее универсальным среди других методов, позволяюших получать современные и точныле данные, разрабатывать и обосновывать рекомендации, которые будут соответствовать реальной ситуации на рынке. Подтверждено, что данный метод продвижения Интернет-продукта является оптимальньм в соотношении точности данных, времени и усилий, затраченных на его внедрение.

Ключевые слова: Интернет-продукт, маркетинг социальных сетей, анализ корпоративной деятельности, сочиальные сети, SWОТ-анализ.

The article discusses the features of the use of the Internet in the advertising activities of a real enterprise. the survey was conducted and the need to use modern Internet tools was substantiated. Emphasizes the need for a more thorough study of social media marketing as the optimal method of promoting an Internet product for enterprises of various scales. This work 
analyzes activities in social networks and promotes the Internet product through them on the example of an existing business entity in an uncertain competitive environment. To analyze the company's work, a SWOT analysis was carried out to identify weaknesses and strengths. This type of analysis allows you to help the organization to see and evaluate all the factors influencing decision-making, as well as to determine the possibilities of development.The increase of network users at the moment has made advertising on the Internet a powerful tool for influencing people and forming public opinion. That is why this type of advertising develops very quickly. As a result, the vast majority of companies use Internet advertising to advertise their own products. That is, the need to use this type of advertising is due to modern market trends. This study examines the problem of using the Internet in advertising activities. It is suggested that the use of social media marketing is the most universal method of promoting an Internet product, emphasizes the urgency of using this method to provide recommendations for enterprises of various scales. It has been proved that the relevance and necessity of using this method contributes to increasing the competitiveness of a business entity in terms of providing recommendations for enterprises of various sizes in today's business - an environment where social media marketing is the most universal among other methods that allows you to obtain up-to-date and accurate data, develop and substantiate recommendations that will correspond to the real situation in the market. It is substantiated that this method of promotion of the Internet product is optimal in the ratio of data accuracy and time and effort spent on its implementation.

Key words: internet product, social media marketing, enterprise activity analysis, social networking, SWOT analysis.

Постановка проблеми. У сучасних умовах мережа Інтернет набула величезних масштабів та має неабиякий вплив на людське життя. Інтернет охоплює нашу буденність усе глибше, включаючи навчання, роботу, спілкування тощо. Збільшення користувачів мережі зробило рекламу в Інтернеті потужним знаряддям для впливу на людей та формування громадської думки. Саме тому такий вид реклами розвивається дуже швидко. У результаті переважна більшість компаній для рекламування власних продуктів використовує саме Інтернет-рекламу. Тобто необхідність використання саме цього виду реклами зумовлена сучасними тенденціями ринку. У даному дослідженні проводиться вивчення проблеми застосування мережі Інтернет у рекламній діяльності. Наводиться припущення, що використання соціального медіамаркетингу $\epsilon$ найбільш універсальним методом просування Інтернет-продукту, наголошується на актуальності використання цього методу для надання рекомендацій для підприємств різного масштабу. Соціальний медіамаркетинг є найбільш універсальним серед інших методів, він дає змогу отримати актуальні та точні дані, розробити висновки, які відповідатимуть дійсній ситуації на ринку. Даний метод просування Інтернет-продукту $є$ оптимальним у співвідношенні точності даних і витрат часу та зусиль на його проведення. У роботі проводиться аналіз за допомогою опитування. Наголошується на необхідності більш ретельного вивчення соціального медіамаркетингу як оптимального методу просування Інтернет-продукту для підприємств різного масштабу.

Аналіз останніх досліджень і публікацій. Дослідженням застосування мережі Інтернет у рекламній діяльності займалися багато вітчизняних та зарубіжних науковців. Деякі з авторів розглядали переваги та недоліки різних інструментів медіамаркетингу та надавали рекомендації щодо їх використання. Але, незважаючи на значний внесок учених у розвиток даного питання, на українських підприємствах увага впливу SММ приділяється недостатньо.

Формулювання цілей статті. Мета проведеного дослідження i, як результат, статті полягає в аналізі особливостей застосування сучасного інструментарію (Інтернету) в рекламній діяльності суб'єкта господарювання з метою прийняття грамотних управлінських рішень.

Виклад основного матеріалу. Застосування мережі Інтернет у рекламній діяльності будь-якого підприємства сприяє формуванню ефективної стратегії дій та прийняттю грамотних управлінських рішень. Як науковці-теоретики, так і фахівці-практики позитивно оцінюють вплив інструментарію Інтернету на господарську 
діяльність суб'єктів господарювання в умовах конкурентного бізнес-середовища. Так, І. Успенський уважає, що «Інтернет має унікальні характеристики, які суттєво відрізняються від характеристик традиційних інструментів маркетингу. Одна з них це його гіпермедійна природа» [2]. Тобто він каже, що Інтернет-маркетинг $є$ лише новим напрямом маркетингу в середовищі мережі Інтернет. І.Д. Падерін визначає поняття Інтернет-маркетингу як технологію маркетингу за допомогою комп'ютерних мереж та систем [1]. М.В. Макарова висловлює думку про те, що «Інтернет-маркетинг є лише складником маркетингової стратегії фірми», зазначаючи, що він «допомагає вирішувати лише ті питання, які будуть ефективними з погляду доходів і витрат» [2]. Таким чином, можна сказати, що на разі немає чітко сформульованого визначення. Більшість учених не може сказати, яке місце Інтернет-маркетинг займає, та зводить усе до Інтернет-реклами. Інформацію про особливості використання SMM можна знайти у практикуючих маркетологів. М. Кун описав кейси, в яких підприємства успішно використовували соціальні мережі [6]. А про бар'єри впровадження SMM розказав у своїй роботі Н. Міхаеліду [7].

Переважна більшість науковців не виокремлює його (Інтернет) як окрему наукову галузь.

Протягом рекламування власного продукту в Інтернеті необхідно вибрати певний метод реклами. Серед різних методів рекламування продуктів в Інтернеті оптимальним варіантом виступає соціальний медіамаркетинг (SMM). Такий метод реклами має велику кількість переваг, найголовнішою з них виступає те, що соціальні мережі надають багато інформації про власних користувачів, дають змогу таргетувати до найдрібніших подробиць, що практично неможливо зробити за допомогою інших інструментів. Соціальний медіамаркетинг актуально застосовувати на підприємствах будь-якого масштабу, при цьому отримані аналітичні дані будуть точними та репрезентативними [4]. У даній роботі проводиться аналіз діяльності у соціальних мережах та просування Інтернет-продукту через них на прикладі IT-компанії Rich Media Systems.

TOB Rich Media Systems - це швидко зростаюча IT-компанія, що базується на продуктах і активно бере участь у створенні та розвитку проєктів електронної комерції. Нині компанія займається декількома проєктами, але найголовнішим є Online-stylist. Даний проєкт пропонує альтернативні варіанти стильних нарядів, які носять відомі знаменитості, блогери та впливові особи. Головним завданням проєкту можна назвати такий тезис: «Для того щоб виглядати вишукано та стильно, не обов'язково витрачати всі свої гроші на одяг», адже компанія співпрацює з Інтернет-сервісом Amazon та такими магазинами, як ASOS, Bershka, Next та ін. Проєкт має власний сайт, що націлений на просування товарів із магазинів, з якими співпрацює компанія.

Для аналізу роботи компанії, виявлення слабких та сильних сторін був проведений SWOT-аналіз. Даний вид аналізу дає змогу допомогти організації побачити та оцінити всі чинники, що впливають на прийняття рішень, а також визначити можливості розвитку. Традиційно для проведення SWOT-аналізу необхідно оцінити такі чотири групи факторів:

- сильні сторони підприємства;

- слабкі сторони підприємства;

- можливості підприємства;

- загрози підприємству.

За наведеними вище факторами був проведений SWOT-аналізу для TOB Rich Media Systems i виявлено, що до сильних сторін компанії можна віднести:

- напрацьовану клієнтську базу;

- диверсифікований бізнес;

- висококваліфікований персонал;

- велике портфоліо робіт, напрацювань. 
До слабких сторін можна віднести:

- невелику кількість працівників;

- постійний ріст фірм-конкурентів з аналогічними продуктами;

- високу конкуренцію у сегменті.

Можливостями компанії можна назвати:

- пошук нових шляхів збуту;

- налагодження співпраці з постійними клієнтами;

- просування компанії та ії проєктів через соціальні мережі;

- розширення клієнтської бази за рахунок упізнаваного логотипу;

- можливості вузької спеціалізації.

До загроз компанії можна віднести:

- цінові війни з конкурентами;

- вихід на ринок нових гравців;

- мінливість технологій.

Аналізуючи діяльність компанії, можна дійти висновку, що ведеться правильна робота у сфері IT та налагоджена постійна співпраця з партнерами. I єдине, чому потрібно приділити більше уваги - це маркетинг. Успіх маркетингу для IT-компанії залежить від комплексного аналізу ринку, виробництва Інтернет-продукту, аналізу систем і каналів реалізації, реклами продукту. Важливо здійснювати маркетингове планування.

TOB Rich Media Systems як основних рекламоносіїв вибирає воронку продаж та email-маркетинг, оскільки це вважається ефективним каналом для реклами. Розсилки ефективно повертають користувачів на сайт - вони знову приходять купувати продукт. Email-маркетинг має найбільшу потенційну базу клієнтів. Воронка продажів - це шлях, який проходить споживач від моменту залучення його уваги до вашої пропозиції до моменту покупки. Автоматична воронка продажів особливо ефективна під час просування бізнесу в Інтернеті. Перш за все, зважаючи на технічні можливості вебсайтів і рекламних майданчиків. Якщо потенційного клієнта не влаштувало рекламне оголошення, можна показати йому інше, «відпрацювавши» тим самим заперечення. Тоді як вуличний банер, який не сподобався перехожому, замінити не вийде [5].

Проблема, з якою стикається компанія, - невеликий приріст аудиторії до проєктів, що вона розробляє. За останні пів року приріст аудиторії становив лише $34,5 \%$, що $є$ дуже малим показником. Із цього можна зробити висновок, що етаil-розсилки неефективно використовувати в процесі просування Інтернет-продукту. Для підтвердження даної теорії були зібрані дані методом опитування, що охопило 150 осіб.

Першим питанням, яке необхідно дослідити, став рівень популярності електронної пошти серед користувачів мережі, тобто чи користуються даною мережею опитувані та чи $\epsilon$ вона для них актуальною. Результати показали, що $87,5 \%$ опитуваних дійсно користуються електронною поштою (рис. 1).

Наступним досліджуваним питаннями стали періодичність, з якою користувачі отримують етаil-розсилки, та рівень зацікавленості у такому виді реклами. Результати опитування показали, що, незважаючи на те що періодичність, з якою користувачі отримують рекламні листи на пошту, є досить високою (щодня або декілька разів на тиждень), такий вид реклами рідко може дійсно зацікавити (рис. 2).

Для такої реклами важливою $є$ велика кількість аспектів: вид товару, що рекламується, креативність рекламного оголошення, текст, актуальність, контент, що його наповнює, та ін. (рис. 3).

Отже, можна зробити висновок, що ефективність реклами, яка здійснюється через email-розсилки, на даний момент є низькою. Дане припущення було підтверджено за допомогою проведеного опитування. Цільова аудиторія не звертає увагу на даний тип реклами, отже, можна створити таку діаграму (рис. 4). 
Чи користуєтеся ви електронною поштою?

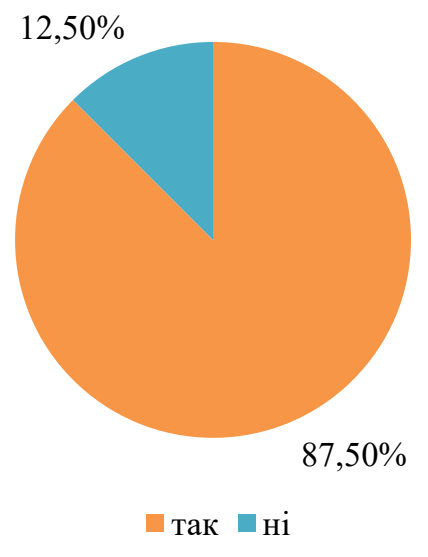

Рис. 1. Кількість опитуваних користувачів, щчо користуються електронною поштою

Джерело: розраховано автором

Як часто вам на пошту приходять рекламні оголошення?

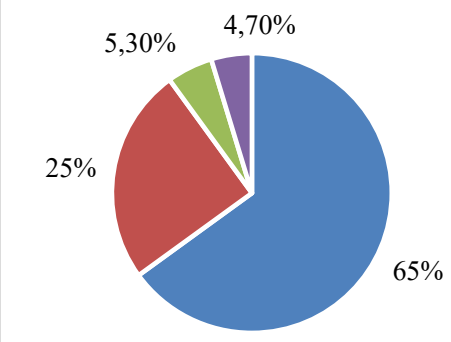

щодня

- декілька разів на тиждень

- декілька разів на місяць

- раз на місяць та рідше

Рис. 2. Періодичність, з якою користувачі отримують рекламні листи Джерело: розраховано автором

Чи може вас зацікавити такий вид реклами

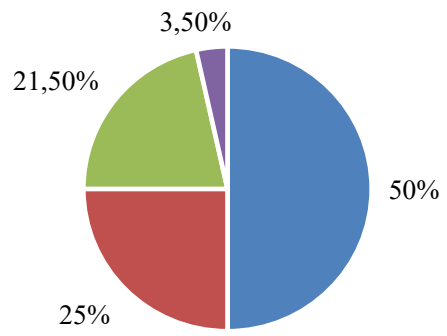
- ні
- залежить від товару, що рекламується
- залежить від рекламного оголошення (креатив, текст та ін.)

Pис. 3. Рівень зачікавленості користувачів в етаіl-розсилках Джерело: розраховано автором 


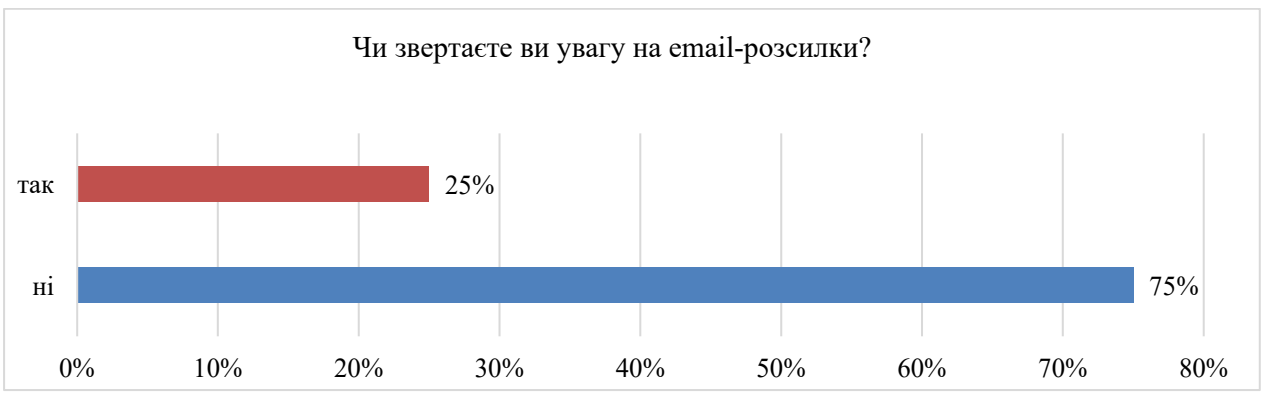

Рис. 4. Зацікавленість користувачів в етаіl-розсилках

Докерело: розраховано автором

За результатами опитування можна зробити висновок, що необхідно шукати нові шляхи залучення аудиторії, а тому важливо розуміти, для яких саме користувачів Інтернет-продукт, що розробляє ТОВ Rich Media Systems, буде цікавим. Для цього був проведений аналіз цільової аудиторії проєктів компанії, тобто аналіз групи людей, на кого необхідно орієнтувати продукти та рекламу компанії (рис. 5).

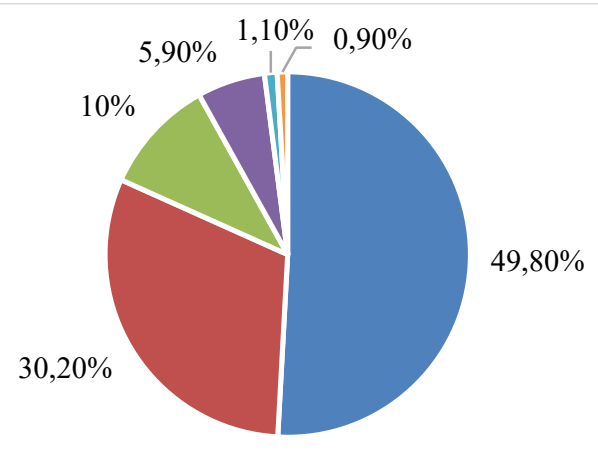

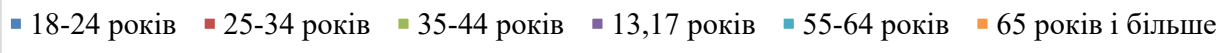

Рис. 5. Цільова аудиторія для Інтернет-продуктів компанії

Джерело: розраховано автором

Методом опитування користувачів було визначено, що цільовою аудиторією проєктів TOB Rich Media Systems $є$ жінки, більшість яких проживає у Великобританії, віком 18-34 років (рис. 5). Таким чином, аудиторія молода, а молодь активно користується соціальними мережами, що підтвердило опитування, яке охопило 130 осіб і було проведено серед представниць саме такого сегменту аудиторії (рис. 6).

Соціальна мережа є каналом маркетингової комунікації, що об'єднує споживача і маркетолога відповідно до попиту та пропозиції продукції, яку виготовляє компанія [3]. Для того щоб краще розуміти рівень ефективності реклами у соціальних мережах, також було проведено опитування. Із нього можна зробити висновки, що періодичність, з якою користувачі соціальних мереж бачать рекламу є дуже високою, щодня (рис. 7); ефективність такого виду реклами порівняно 3 email-розсилками $\epsilon$ вищою. 


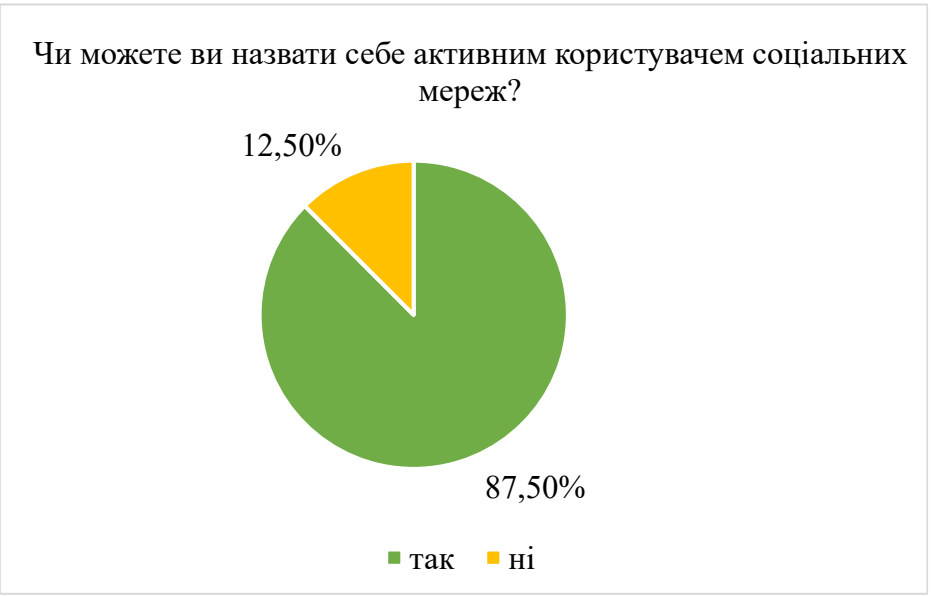

Рис. 6. Рівень залучення иільової аудиторії в користування сочіальними мережами Джерело: розраховано автором

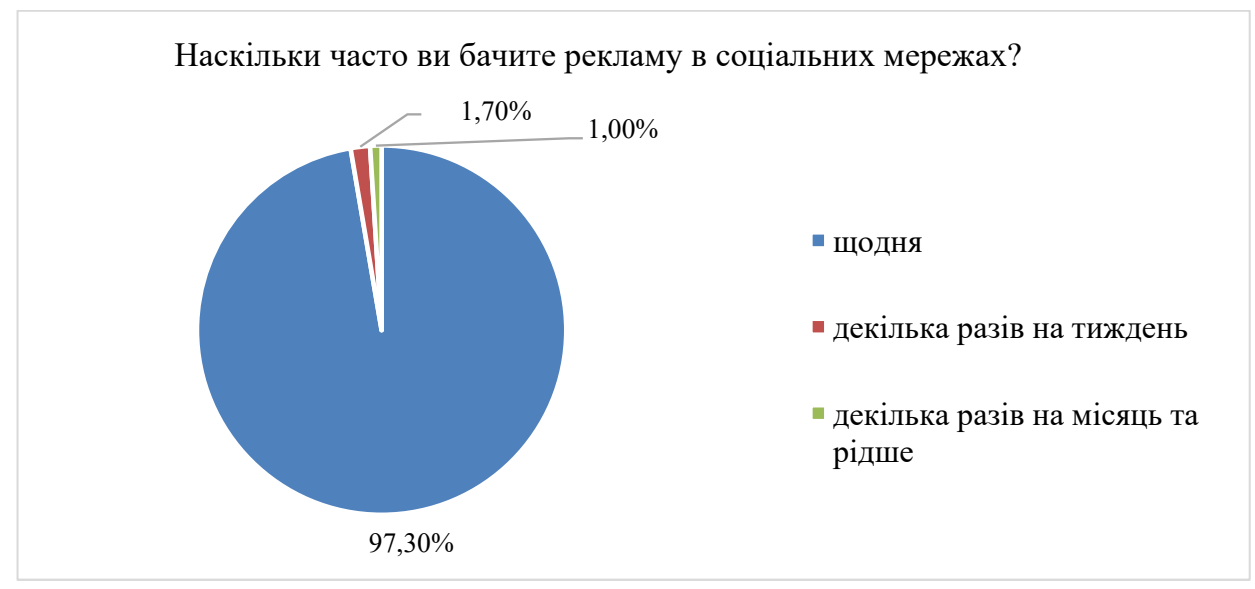

Рис. 7. Періодичність, з якою користувачі бачать рекламу в Інтернеті Джерело: розраховано автором

Ефективність такого виду реклами порівняно з етаil-розсилками $є$ вищою, адже більшість опитуваних реклама у соціальних мережах може зацікавити, незважаючи на величезну низку чинників, таких як вид товару, що рекламується, креативність рекламного оголошення, текст, актуальність, контент, що його наповнює, та ін. (рис. 8).

Сьогодні існує велика кількість соціальних мереж, якими активно користуються мільйони людей щодня. Наприклад, кількість активних користувачів Facebook у 2020 p. становила 2,6 млрд осіб. Це більше третини всього населення планети, й їх кількість продовжує зростати. Тому необхідно зрозуміти, яка саме соціальна мережа має стати пріоритетною для просування Інтернет-продукту TOB Rich Media Systems (рис. 9).

Методом опитування визначено, що найпопулярнішою соціальною мережею серед користувачів на даний момент $\epsilon$ Instagram, тому саме цю соціальну мережу необхідно використовувати для просування Інтернет-продукту компанії. 


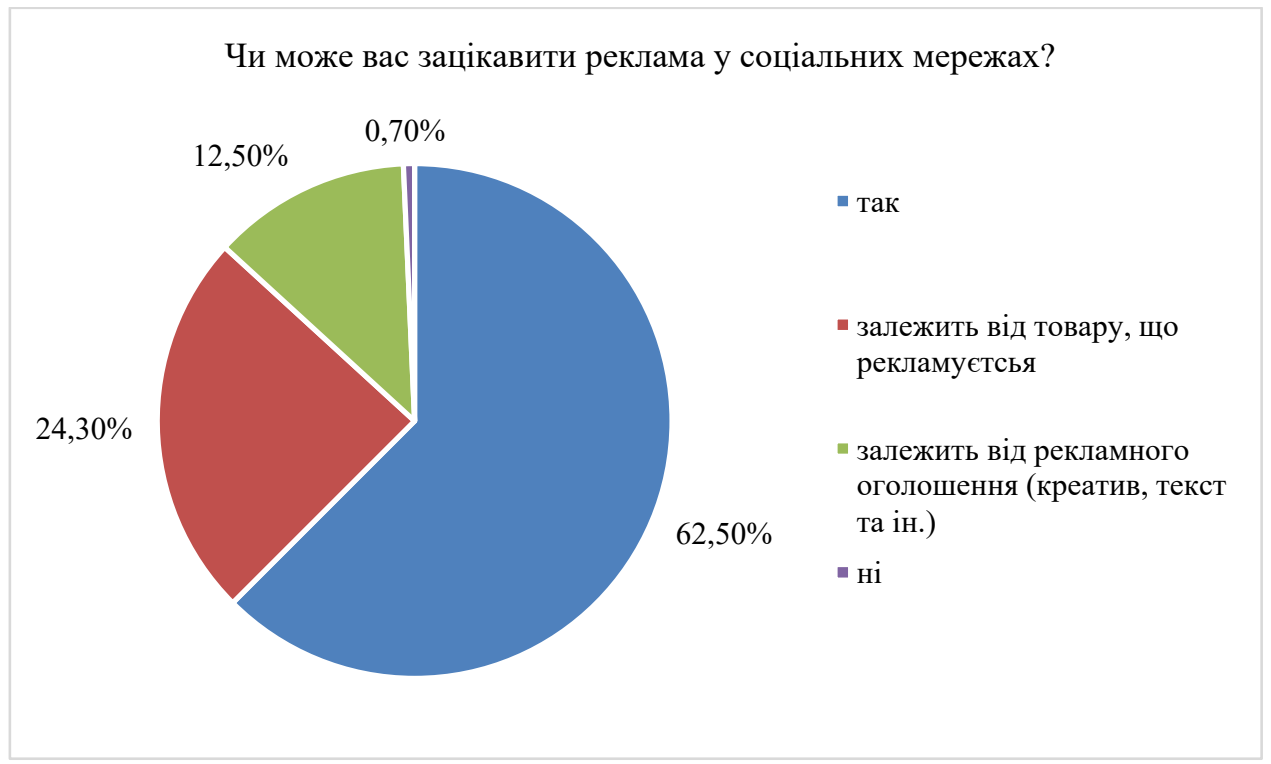

Рис. 8. Рівень зацікавленості користувачів у рекламі у соціальних мережах Джерело: розраховано автором

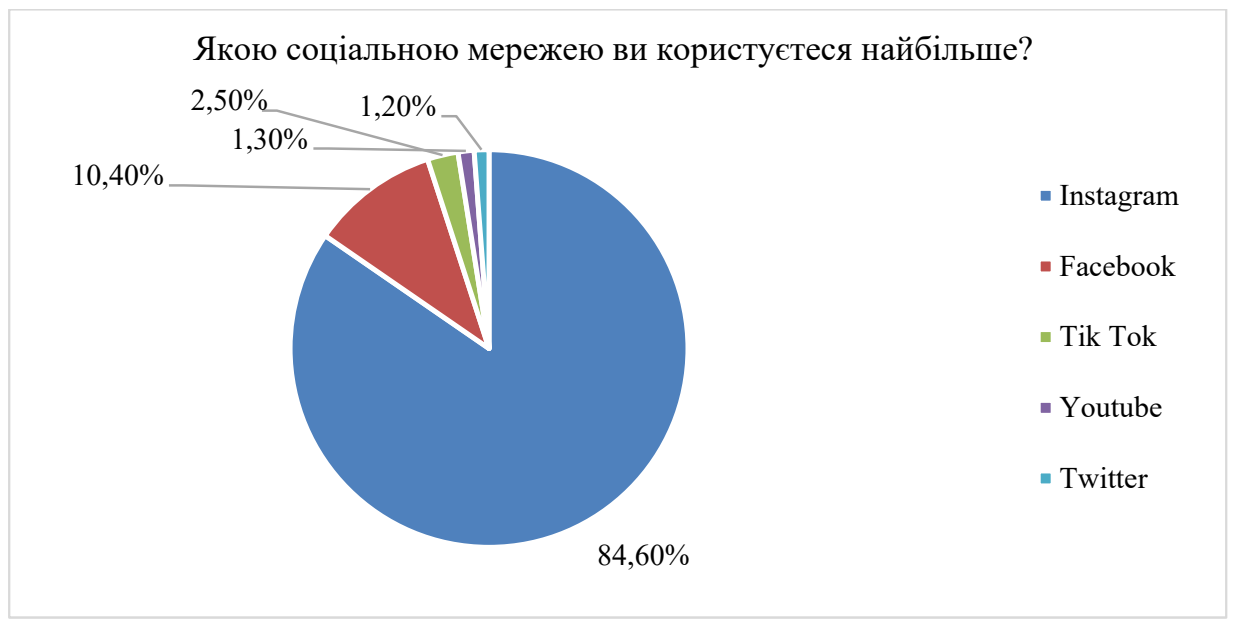

Рис. 9. Аналіз найпопулярнішої сочіальної мережі серед користувачів Джерело: розраховано автором

Висновки. Таким чином, використання соціального медіамаркетингу є найбільш універсальним методом просування Інтернет-продукту, що сприяє формуванню ефективної стратегії підприємства та прийняттю грамотних управлінських рішень. Наголошено на актуальності та необхідності використання цього методу, оскільки він сприяє підвищенню конкурентоздатності суб'єкта господарювання в аспекті надання рекомендацій для підприємств різного масштабу в сучасному бізнес-середовищі. Соціальний медіамаркетинг є найбільш універсальним серед інших методів, який дає 
змогу отримати актуальні та точні дані, розробити та обгрунтувати рекомендації, що відповідатимуть реальній ситуації на ринку. Даний метод просування Інтернет-продукту є оптимальним у співвідношенні точності даних та витрат часу і зусиль на його проведення.

\section{Список використаних джерел:}

1. Падерін І.Д. Розвиток Інтернет-маркетингу на підприємствах малого та середнього бізнесу. Економічний вісник Донбасу. 2016. № 1(43). С. 120-124.

2. Лебеденко С.О., Мороз Н.К. Застосування маркетингових Інтернет-інструментів на прикладі державного підприємства «Антонов». Ефективна Економіка. 2018. № 11. C. 10-14. URL: http://www.economy.nayka.com.ua/?op=1\&z=6659 (дата звернення: 02.03.2021).

3. Суровцев О.О. Соціальний медіамаркетинг як маркетингова комунікація підприємств під час виходу на нові ринки. Науковий вісник Ужгородського національного університету. 2016. № 9. C. 145-148.

4. Каптур А.О. Інтернет-реклама: сучасний канал комунікації. Тендениії та перспективи. Інтернаука. 2017. № 8. С. 43-45.

5. Coon M. Social media marketing: successful case studies of businesses using facebook and youtube with an in-depth look into the business use of twitter. Stanford University Press. 2015. Vol. 3. № 1. P. 674-693.

6. Michaelidou N. Usage, barriers and measurement of social media marketing: an exploratory investigation of small and medium b2b brands. Business industrial marketing management. 2011. № 7. P. 1153-1159.

\section{References:}

1. Paderin I.D. (2016) Rozvytok internet-marketynhu na pidpryiemstvakh maloho ta serednoho biznesu [Development of Internet marketing in small and medium enterprises]. Ekonomichnyi visnyk Donbasu, no. 1(43), pp. 120-124.

2. Lebedenko S.O., Moroz N.K. (2013) Zastosuvannia marketynhovykh internet instrumentiv na prykladi derzhavnoho pidpryiemstva «Antonov» [The use of Internet marketing tools on the example of the state enterprise "Antonov"]. Efektyvna Ekonomika (electronic journal), vol. 11, no. 109, pp. 10-14. Available at: http://www.economy.nayka.com.ua/?op=1\&z=6659 (accessed 2 March 2021).

3. Surovtsev O.O. (2016) Sotsialnyi media-marketynh yak marketynhova komunikatsiia pidpryiemstv pid chas vykhodu na novi rynky [Social media marketing as a marketing communication of enterprises when entering new markets]. Naukovyi visnyk Uzhhorodskoho natsionalnoho universytetu, no. 9 , pp. $145-148$.

4. Kaptur A.O. (2017) Internet-reklama: suchasnyi kanal komunikatsii. Tendentsii ta perspektyvy [Internet advertising: a modern communication channel. Trends and prospects]. Mizhnarodnyi naukovyi zhurnal «Internauka», no. 8, pp. 43-45.

5. Coon M. (2015) Social media marketing: successful case studies of businesses using facebook and youtube with an in-depth look into the business use. Stanford University Press, vol. 3, no. 1, pp. 674-693.

6. Michaelidou N. (2011) Usage, barriers and measurement of social media marketing: an exploratory investigation of small and medium b2b brands. Business industrial marketing management, no. 7, pp. 1153-1159. 